\title{
The development of socio-motivational dependency from early to middle adolescence
}

\author{
Danilo Jagenow*, Diana Raufelder and Michael Eid \\ Methods and Evaluation Division, Department of Education and Psychology, Freie Universität Berlin, Berlin, Germany
}

\section{Edited by:}

Barbara McCombs, University of Denver, USA

\section{Reviewed by:}

Kuan-Chung Chen, National University of Tainan, Taiwan

Maciej Karwowski, Academy of

Special Education, Poland

\section{${ }^{*}$ Correspondence:}

Danilo Jagenow, Methods and Evaluation Division, Department of Education and Psychology, Freie Universität Berlin, Habelschwerdter Allee 45, 14195 Berlin, Germany e-mail: danilo.jagenow@fu-berlin.de
Research on students' motivation has shown that motivation can be enhanced or undermined by social factors. However, when interpreting such findings, interindividual differences, and intraindividual changes underlying students' perception of peers and teachers as a source of motivation are often neglected. The aim of the present study was to complement our understanding of socio-motivational dependency by investigating differences in the development of students' socio-motivational dependency from early to middle adolescence. Data from 1088 students on their perceptions of peers and teachers as positive motivators when students were in seventh and eighth grade were compared with data of the same sample 2 years later. Latent class analysis supported four different motivation types (MT): (1) teacher-dependent MT, (2) peer-dependent MT, (3) teacher-andpeer-dependent MT, and (4) teacher-and-peer-independent MT. Latent transition analysis revealed substantial changes between the groups. The perceived teacher influence on students' academic motivation increased from early to middle adolescence. Divergent roles of peers and teachers on students' academic motivation are discussed.

Keywords: socio-motivational dependency, person-oriented approach, latent transition analysis, teacher-student relationship, student-student relationship

\section{INTRODUCTION}

Although the association between social factors and students' motivation has been studied extensively in the past (e.g, Juvonen and Wentzel, 1996; Wentzel, 1998, 2009b; Reeve, 2006; Deci and Ryan, 2008; Ladd et al., 2009; Wentzel et al., 2012), it is still unclear whether these relationships undergo important developmental changes across early to middle adolescence. Therefore, the present study employed a longitudinal design to better understand intraindividual changes regarding peers and teachers as sources of motivation.

Raufelder et al. (2013c) examined interindividual differences in how important teachers and peers are in shaping the level of students' academic motivation. Within the school context, students' motivation can be predominantly affected by peers' motivation, learning behavior, and social support or teachers' motivation and support or both (Wentzel, 2009a,b; Raufelder et al., 2013c). However, this was not true for all students because a considerable part of students reported that their motivation is not affected by teachers and peers. Research supported the concept of four different types of what is termed as socio-motivational (in-)dependency ${ }^{1}$ : (1) a teacher-dependent motivation type (MT), (2) a peer-dependent MT, (3) a teacher-and-peer-dependent MT, (4) a teacher-andpeer-independent MT (Raufelder et al., 2013c; Hoferichter et al., 2014). The teacher-dependent MT is described as a student whose academic motivation is predominantly affected by teacher's characteristics and perceived support, such as awareness of the

\footnotetext{
${ }^{1}$ To clarify, Raufelder et al. (2013c) use the term "dependency" referring to motivation and thus differently, than the term is used in the context of learning-theoretical perspectives.
}

student's abilities or the teacher's own engagement, motivation and interest in the subject. In contrast, the peer-dependent MT represents students whose motivation is predominantly affected by the school-based behavior of their peers, such as interests, motivation or the amount of effort they put into studying. In turn, the teacher-and-peer-dependent MT is a mixed type because academic motivation of such students is affected by both teachers' and peers' characteristics. Hoferichter et al. (2014) compared a sample of Canadian and German students and suggest that the teacher-and-student dependence presupposes the developing social competencies more than the other types. Finally, the teacherand-peer-independent MT is unaffected by teachers' and peers' motivation, learning behavior, and support. (Jagenow et al., 2014) compared the various forms of socio-motivational dependency based on different school-related variables. Despite the assumption that the sources of motivation of the independent type lies in the individual themselves (i.e., intrinsic motivated) these students showed lowest level of academic motivation while lowest test anxiety values. The authors suggest that the independent type might at risk of school failure.

\section{LITERATURE REVIEW}

Literature, investigating the link between relationships at school and motivation points to the existence of different forms of support teachers and peers can provide. Wentzel et al. (2010, 2012) distinguish between multiple classroom support: providing help, providing emotional support, creating a save environment, and communication of expectations and values. Raufelder et al. (2013c) interest was not only in support but also in students' perceptions of teachers' motivation for the subject, the 
awareness of students' abilities or success with the material, and peers' learning behavior. Students' perception of these important classroom aspects is affecting most individuals' motivation and achievement behavior. For example, when teachers show motivation for their subjects, students are expected to show more motivation as well, which is true for the subtypes teacherdependent and teacher-and-peer-dependent MT (Raufelder et al., 2013c). However, it should be underlined that there are many students, whose motivation is unaffected by teachers and peers at allthe teacher-and-peer-independent MT.

Research has shown that the level of students' academic motivation changes as they move through adolescence (Wentzel, 2009b). Namely, the motivation of many students decreases with each school year, due to changes both in social processing and in the school environment (Eccles and Midgley, 1990; Wigfield et al., 1998). Interestingly, students react in different ways to these changes: while some individuals start to resile from achievement situations and avoid such contexts whenever possible, others might not be negatively affected by the changes at all (Wigfield and Eccles, 2001). In other words, they show comparable levels of school achievement and motivation to learn throughout adolescence (Deci and Ryan, 2000) which seem to be independent of the teachers who instruct them or the classmates who surround them (Raufelder et al., 2013b).

A framework that helps to understand these divergent findings in adolescent motivation is 'developmental contextualism' (Lerner, 1986, 1991, 1998), that is, a theory of human ontogenetic development that focuses on the changing relations or coactions between the developing individual and his or her context. This theory argues that the development of the person-in-context is depicted as a function of dynamic processes embedded in multilevel interactions between a person and his or her contexts. This suggests that in the context of academic motivation, teacherstudent relationships and student-student relationships might play a critical role in adolescence. In line with the work of Hamre and Pianta (2001), who applied developmental contextualism to better understand the importance of the teacher-student relationship for academic motivation, academic motivation can be understood to be one component of a dynamic process involving the interplay between the developing adolescent and his or her school context (i.e., teacher relationships, peer relationships). Taken together, the evidence of interindividual differences in students' socio-motivational dependency and the contextual changes over time suggests that also intraindividual changes within the developing individual might take place.

The study by Raufelder et al. (2013c) is one of the few that examined the joint influence of teachers and peers on students' academic motivation (see also Wentzel et al., 2010) using a person-oriented rather than a variable-oriented approach in this area of research. The variable-oriented approach focuses on purely additive effects of the variables of interest (Davidson etal., 2010) by ignoring interactions between the variables (Rosato and Baer, 2012; Raufelder et al., 2013d). Furrer and Skinner (2003) conducted a person-oriented design study and investigated the importance of children's relatedness (e.g., feelings of acceptance, interpersonal support) to teachers and parents. The authors found that positive experiences in one relational context may buffer the impact of negative relational experiences in another context. This study also demonstrated an important advantage of the person-oriented approach, that is, it is designed to identify subgroups in the population that are characterized by a particular combination of values on a set of variables (Bergman and Magnusson, 1997; von Eye and Bergman, 2003). Furthermore, the person-oriented approach aims to group individuals into categories, where each contains individuals that are similar to each other and different from the individuals in other categories (Muthén and Muthén, 2000).

In the context of emotional and behavioral attitude toward school, the relationships that students have with their classroom peers have been repeatedly shown to play a critical role (e.g., Ryan, 2001; Furrer and Skinner, 2003; Zimmer-Gembeck et al., 2006; Ladd et al., 2009; Wentzel et al., 2010). For example, in a longitudinal study of adolescents, students who had better relationships with peers at school were more likely to display greater emotional engagement at school (Furrer and Skinner, 2003). Furthermore, the adolescents' peer group context predicts the levels of school achievement and intrinsic school values (e.g., enjoyment, linking) after 1 year (Ryan, 2001). Ladd et al. (2009) argued that peer relationships promote students' motivation by increasing student participation, and providing support and assistance, which increases students' school engagement, as well as the overall levels of learning and academic competence.

Research on the development of social relationships during childhood and adolescence found that with the beginning of adolescence individuals spent a large part of their time in school and interact with their peers. Thus, it is likely that peers have an increasing impact on students' school engagement as have teachers or parents (e.g., Csikszentmihalyi and Larson, 1984; Brown, 1990; Hymel et al., 1996; Rohrbeck, 2003; Levitt, 2005). One possible explanation for this behavior is that young adolescents have strong needs for social identity and spending time with peers satisfies these needs stronger than spending time with family members (Csikszentmihalyi et al., 1977; Youniss, 1980). Moreover, this period of time in one's life is accompanied by significant changes in the nature of relationships with peers (e.g., Dubow et al., 1991; Larson and Richards, 1991). For example, in a study with children and adolescents, participants perceived parents and friends as equally supportive for the ages 9-15 but for the years 16-18 friends' support exceeded parents' support (Bokhorst et al., 2010). Dubow et al. (1991) found that changes from third through fifth graders in the received peer support were closely related to changes in their school adjustment 2 years later, which reflects the growing influence of peers during early adolescence. Other findings suggest, that adolescents whose friends do well in school or have a positive attitude toward school show fewer academic problems (e.g., disengagement) than those whose friends are less academically engaged (Crosnoe et al., 2003). Overall, it is reasonable that during adolescence peers play an increasingly stronger role in shaping one's academic motivation because they satisfy one's needs for close relationships, emotional, or behavioral support, as well as influence one's attitude toward school.

In contrast, the quality of relationships with adults declines from the age of 12 to 18 (e.g., Kenny et al., 2013). In spite of the 
fact that teachers are the primary adult figures in the academic context, support from teachers declines from the age of 12 to 18 (Bokhorst et al., 2010). Moreover, the strength of the association between teachers' support and students' motivation decreases with each year passing (Goodenow, 1993). A critical time point is when students move from elementary to secondary school (Eccles et al., 1993), at which point the decline in the teacher-student relationship quality coincides with a growing need for close emotional relationships with adults from outside of the home environment (Midgley et al., 1989; Raufelder, 2007; Raufelder et al., 2013a).

There is a large body of research focusing on the link between teacher-student relationships and important academic outcome (e.g., Baker, 2006; Zimmer-Gembeck et al., 2006; Davidson et al., 2010; Wentzel et al., 2010; Hughes, 2012). Positive teacher-student relationships are associated with higher academic skills (e.g., Baker, 2006), classroom motivation (Wentzel, 1998), and social engagement (Gest et al., 2005). For example, middle school students tend to be more academically active in the classroom when they get positive feedback from their teachers (Skinner and Belmont, 1993), when they believe that their teachers care about them (Roeser et al., 1996), or when they are well-liked by their teachers (Wentzel and Asher, 1995). However, only few longitudinal studies have investigated the developmental changes of those associations (e.g., Skinner et al., 1998; Murdock et al., 2000; Hamre and Pianta, 2001; Furrer and Skinner, 2003). Hence, very little is known about the changes in the importance of these relationships for students' motivation and school achievements after grade eighth. "Although we generally know more about these relationships at the elementary level, there is good reason to think that they are especially critical during secondary school" (Gehlbach et al., 2012, p. 692).

\section{RESEARCH OBJECTIVES AND HYPOTHESES}

The aim of the current study was twofold. The first aim was to examine interindividual differences in adolescent students' sociomotivational dependency. Specifically, we tested whether the four types of socio-motivational dependency found in seventh and eighth graders (Raufelder et al., 2013c) can be identified within the same cohort approximately 2 years later. The second aim of the present study was to describe the intraindividual development of students' socio-motivational dependency from early to middle adolescence. We examined this age group because students' motivation declines after the transition to secondary school and continues to do so for the first 3 years of high school (Harter, 1996), reaching its nadir in the ninth grade (Eccles and Wigfield, 1998).

Based on these preliminary studies, the empirical findings outlined above the present study examined the following two hypotheses:

\section{Hypothesis 1}

(A) The same four types of socio-motivational dependency that were found in grade seven and eight (Raufelder et al., 2013c) can be identified in grade nine and 10. (B) More specifically, based on findings that peers become more important while adults become less important agents during adolescence (e.g., Juvonen and Wentzel, 1996), the size of the teacher-dependent MT group should decrease and the size of the peer-dependent MT should increase from early to middle adolescence.

\section{Hypothesis 2}

Based on Lerner's contextualism considering changing relations or coactions between the developing individual and his or her context over time (Lerner, 1986, 1991, 1998), it was hypothesized that individuals will vary in their socio-motivational dependency from early to middle adolescence. In particular, we assumed that the three socially dependent MTs would show higher fluctuation rates compared to the teacher-and-peer-independent MT.

\section{MATERIALS AND METHODS PARTICIPANTS}

We initially examined 1088 participants aged $12-15$ years (mean age $=13.7$ years, $\mathrm{SD}=0.53$ years; $53.9 \%$ girls), who were sampled from a group of seventh- and eighth-grade students from 23 randomly chosen secondary schools in a suburban, predominantly middle-class community in Brandenburg (Germany). At the second time point, $\sim 2$ years later, 783 students (mean age $=15.3$ years, $\mathrm{SD}=0.50$ years; $53.5 \%$ girls) of the initial sample remained in the study $(72.0 \%$ retention rate; sex, age, and MT at the first occasion of measurement were no predictors of drop-out.). Data on ethnicity was not collected due to low ethnic diversity in Brandenburg and socio-economic information was not gathered due to laws in Germany prohibiting the collection of such data via a third party. The study was approved by the Department of Education, Youth and Sports of Brandenburg. Consent was obtained from parents, and assent was provided by the participants. Parents and students were informed that the survey would be voluntarily, anonymous and confidential.

\section{PROCEDURE AND MEASURES}

At the beginning of the German school year, self-report measures of students' perception of peers and teachers as positive motivators were collected during class time on two consecutive days. For this purpose, two subscales from the Relationship and Motivation Scale (REMO; Raufelder et al., 2013b) were used: (1) 'Teachers as positive motivators' (TPM, six items; e.g., "If the teacher is really interested in the topic, I am interested as well"; internal consistency at the first time point (T1): Cronbach's $\alpha=0.78$; internal consistency at the second time point (T2): Cronbach's $\alpha=0.78)$, (2) 'Peers as positive motivators' (PPM, nine items; e.g., "If my friends want to do better at school, I also want to do better"; internal consistency at T1: Cronbach's $\alpha=0.80$; internal consistency at T2: Cronbach's $\alpha=0.83$ ). These two subscales assess the positive influence of teachers and peers on academic motivation, respectively. In both subscales, responses are measured on a 4-point Likert scale ranging from 1 (strongly disagree) to 4 (strongly agree). The same measures were collected again using identical testing procedures after approximately 2 years.

\section{ANALYSIS}

\section{Latent class analysis on the second occasion of measurement}

We employed a latent class approach to identify different groups of socio-motivational dependency at T2. Our analyses are based on the latent class analysis (LCA) that led Raufelder et al. (2013c) to identify four MT at the first occasion of measurement. In 
their analysis parcels from the PPM and TPM items were created and dichotomized. Therefore, prior to conducting LCA, parcels were create from the nine items of the REMO subscale PPM and from the six items of the REMO subscale TPM determined by the initial factor analysis of the REMO validation study (Raufelder et al., 2013b). Little et al. (2002) list three reasons that parceling can be advantageous over using the original items: (1) estimating large numbers of items is likely to result in spurious correlations, (2) subsets of items from a large item pool will likely share specific sources of variance that may not be of primary interest, and (3) solutions from itemlevel data are less likely to yield stable solutions than solutions from parcels of items. Based on these considerations as well as the unidimensionality of the Peer-REMO subscales (P-REMO), items of PPM were randomly assigned to parcels. In contrast, the items of TPM were assigned to parcels based on a factor analysis, as the Teacher-REMO subscales (T-REMO) are not unidimensional.

Using LCA, participants can be grouped into classes, in which individuals are assumed to have identical patterns of solution probabilities. For analyzing T2 data several models, where each is differentiated by the number of latent classes, were compared to determine which model best fits the observed data. Using an iterative process, we initially chose a two-class solution and increased the number of classes incrementally until a good fit was achieved. Statistical model fit criteria were employed to determine the optimal number of classes. The statistical criteria used to guide this process were the lowest Akaike Information Criteria (AIC; Akaike, 1973), the lowest Bayesian Information Criteria (BIC; Schwarz, 1978), and the lowest sample-size adjusted BIC (a. BIC). Values of these criteria are useful to compare the fit of one model with the fit of other models. Additionally, the Bootstrap Likelihood Ratio Test (BLRT; McLachlan and Peel, 2000) was conducted to test the statistical significant benefit of a model $(p<0.05)$. The BLRT compares the fit of a model with ' $\mathrm{g}$ ' latent classes versus that with 'g minus one' latent classes (H0). In a Monte Carlo simulation, the BLRT was demonstrated to be a consistent and robust indicator of the presence of additional latent classes (Nylund et al., 2007).

\section{Latent transition analysis}

To investigate individuals' transition between latent classes over time, we employed latent transition analyses (LTA), which combines LCA with autoregressive modeling (specifically Markov models; Langeheine and Van de Pol, 1990), where the latter describes transitions among the classes associated with time passing. Several models were compared to determine which model corresponds best to the observed data. The models differed in their restrictions: the fully restricted model assumes that: (a) conditional probability and (b) class size are the same for each of the classes across time. In contrast, the unrestricted model makes no assumptions about equality of the measurement parameters across the classes and time. Finally, the semi-restricted model involves an assumption that conditional probabilities are invariant but allows the class sizes to be estimated freely across time.

Using an iterative process, we started with a two-class solution for the two occasions of measurement and increased the number of classes incrementally. Additional classes were added until a good fit was achieved. Statistical model fit criteria were used to determine the optimal restriction and number of classes. The statistical criteria used to guide this process were the lowest AIC, BIC, and sample-size adjusted BIC.

To account for missing data, models were estimated with full information maximum likelihood (FIML). All of the models in the present study were analyzed using the statistical software Mplus 7.11 (Muthén and Muthén, 1999-2012).

\section{RESULTS}

\section{LCA FOR THE SECOND OCCASION OF MEASUREMENT}

Table 1 shows model-fit results for the LCA at T2 for the two through five class models. According to the AIC, BIC, and samplesize adjusted BIC (lowest values) the 4-class solution (model 3) had the best fit to our data. Furthermore, the BLRT indicated that model 4 is not superior to model 3 . The classification quality of the model was satisfactory (entropy $=0.68$ ). The entropy ranges from zero to one with higher values indicating a better class separation. To our knowledge, there is no simulation study that allows to define clear boundaries of entropy. The literature often refers to values around 0.60 as moderate (e.g., Vermunt, 2010), but there is no clear rule. Figure 1 shows the estimated conditional class-specific probabilities to agree with the underlying indicator variables. Membership of the 4-class solution was as follows: $17.7 \%$ teacher-and-peer-dependent MT (74 girls and 64 boys), $19.8 \%$ teacher-dependent MT (83 girls and 72 boys), $35.2 \%$ peer-dependent MT, (148 girls and 129 boys), and 27.2\% teacher-and-peer-independent MT (114 girls and 99 boys).

Compared to the class membership from the first occasion of measurement (see Raufelder et al., 2013c), the teacher-and-peerdependent MT decreased by 10.1 percentage points (PPs), whereas the teacher-dependent MT increased by 10.3 PP. The groups of peer-dependent MT (increase by $0.9 \mathrm{PP}$ ) and independent MT (decrease by $0.9 \mathrm{PP}$ ) remained relatively stable.

\section{LTA FOR BOTH OCCASION OF MEASUREMENT}

Table 2 shows the model fit criteria for the LTA for the two through five class models and the three model restrictions. According to the AIC, BIC, and sample-size adjusted BIC (lowest values) the semirestricted model involving a 4-class solution showed the best fit to our data. Results indicated measurement invariance (equality

Table 1 | Model fit results for latent class analysis (LCA) for the second occasion of measurement.

\begin{tabular}{lllll}
\hline & \multicolumn{3}{c}{ Statistical fit criteria } & $\begin{array}{l}\text { Bootstrap } \\
\text { Likelihood } \\
\end{array}$ \\
\cline { 2 - 4 } & AIC & BIC & a. BIC & Ratio Test \\
\hline (1) Model: 2 classes & 6248.939 & 6310.581 & 6269.297 & 0.000 \\
(2) Model: 3 classes & 6096.016 & 6190.850 & 6127.336 & 0.000 \\
(3) Model: 4 classes & $\mathbf{6 0 0 2 . 5 1 1}$ & $\mathbf{6 1 3 0 . 5 3 7}$ & $\mathbf{6 0 4 4 . 7 9 3}$ & 0.000 \\
(4) Model: 5 classes & 6010.158 & 6161.376 & 6053.402 & 0.105
\end{tabular}

AIC, Akaike Information Criteria; BIC, Bayesian Information Criteria; a. BIC, sample-size adjusted Bayesian Information Criteria; BLRT, Bootstrap Likelihood Ratio Test. Statistical fit criteria of the superior model are bold. 


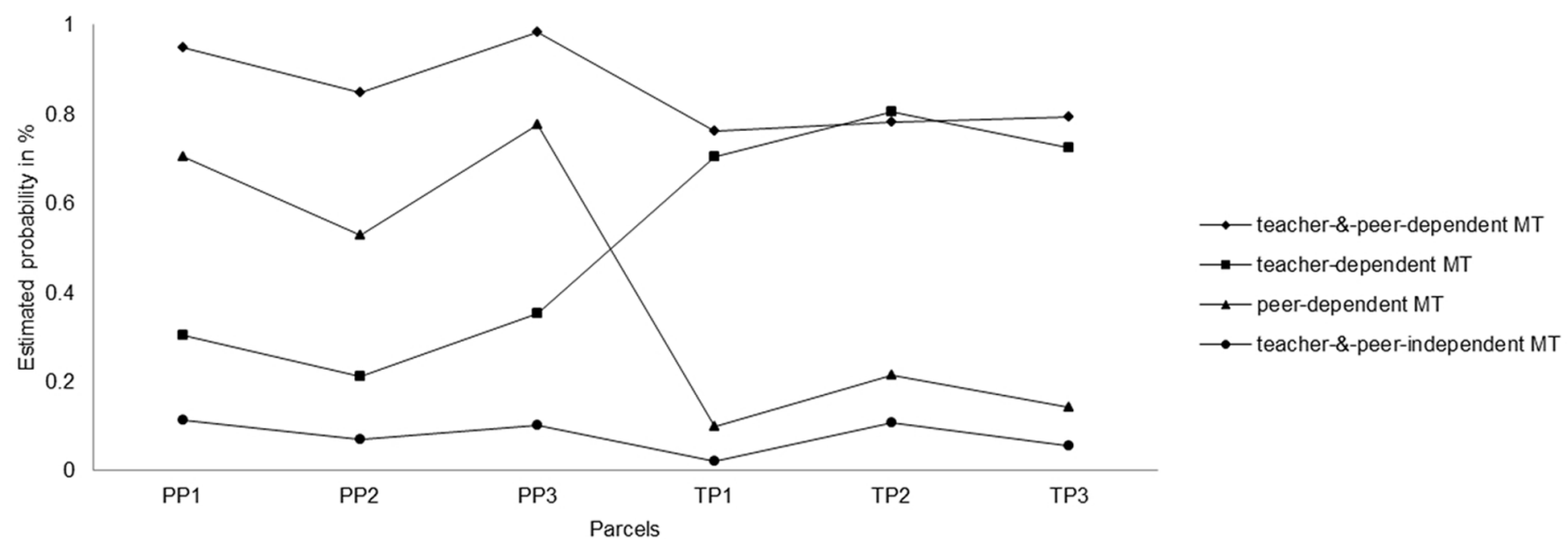

FIGURE 1 | Latent Class Analysis of socio-motivational dependency for the second occasion of measurement. $X$-axis shows three "peers as motivators" parcels (PP1-PP3) and three "teacher as motivators" parcels (TP1-TP3) included in the model analyses. Y-axis shows probability of agreement with the clusters.

Table 2 | Statistical fit results for latent transition models (T1 and T2).

\begin{tabular}{|c|c|c|c|c|c|c|c|c|c|}
\hline \multirow{2}{*}{$\begin{array}{l}\text { Number Of } \\
\text { classes }\end{array}$} & \multicolumn{3}{|c|}{ Fully restricted } & \multicolumn{3}{|c|}{ Semi restricted } & \multicolumn{3}{|c|}{ Unrestricted } \\
\hline & AIC & BIC & a. BIC & AIC & BIC & a. BIC & AIC & $\mathrm{BIC}$ & a. BIC \\
\hline 2 & 13840.5 & 13910.6 & 13866.1 & 13734.2 & 13809.2 & 13761.6 & 13720.5 & 13855.6 & 13769.8 \\
\hline 3 & 13439.2 & 13549.3 & 13479.4 & 13292.7 & 13422.8 & 13340.2 & 13289.7 & 13509.8 & 13370.0 \\
\hline 4 & 13242.9 & 13393.0 & 13297.7 & 13050.3 & 13245.4 & 13121.5 & 13051.4 & 13366.6 & 13166.4 \\
\hline
\end{tabular}

AIC, Akaike Information Criteria; BIC, Bayesian Information Criteria; a. BIC, sample-size adjusted Bayesian Information Criteria. Statistical fit criteria of the superior model are bold.

of conditional probabilities) from T1 to T2. Moreover, a change in class sizes had to be allowed. The classification quality of the model was satisfactory $($ entropy $=0.64)$.

\section{Table 3 | Latent transition probabilities from T1 to T2.}

\begin{tabular}{|c|c|c|c|c|}
\hline \multirow[b]{2}{*}{$\begin{array}{l}\text { Latent class } \\
\text { T1 }\end{array}$} & \multicolumn{4}{|c|}{ Latent class T2 } \\
\hline & $\begin{array}{l}\text { Teacher and } \\
\text { peer-dependent }\end{array}$ & $\begin{array}{l}\text { Peer- } \\
\text { dependent }\end{array}$ & Independent & $\begin{array}{l}\text { Teacher- } \\
\text { dependent }\end{array}$ \\
\hline $\begin{array}{l}\text { Teacher and } \\
\text { peer- } \\
\text { dependent }\end{array}$ & 0.47 & 0.28 & 0.03 & 0.23 \\
\hline $\begin{array}{l}\text { Peer- } \\
\text { dependent }\end{array}$ & 0.13 & 0.58 & 0.21 & 0.08 \\
\hline Independent & 0.02 & 0.19 & 0.68 & 0.11 \\
\hline $\begin{array}{l}\text { Teacher- } \\
\text { dependent }\end{array}$ & 0.10 & 0.03 & 0.40 & 0.47 \\
\hline
\end{tabular}

Probabilities of being in the same class at both occasions of measurement are bold.
Table 3 shows latent transition probabilities based on the estimated model ${ }^{2}$. In the following paragraph, the most vital results are described in more detail. The probabilities of staying in the same latent class at $\mathrm{T} 1$ and $\mathrm{T} 2$ are as follows: 0.68 for the independent MT, 0.58 for the peerdependent MT, and 0.47 for the teacher-and-peer- dependent and the teacher-dependent MT, respectively. Furthermore, if you were a teacher-dependent MT at $\mathrm{T} 1$, the probability of becoming at $\mathrm{T} 2$ an independent MT is 0.40 . If you were a teacher-and-peer-dependent MT at $\mathrm{T} 1$, the probability of becoming at T2 a peer-dependent MT is 0.28 and a teacherdependent MT is 0.23 . All other transition probabilities were below 0.20 .

Table 4 shows an absolute amount of stability and change types from $\mathrm{T} 1$ to $\mathrm{T} 2$, based on model's estimated posterior probabilities. For example, $7.4 \%$ of the sample was a teacherand-peer-dependent MT at $\mathrm{T} 1$ and became peer-dependent MT at T2; 6\% of the sample was teacher-and-peer-dependent $\mathrm{MT}$ at $\mathrm{T} 1$ and became teacher-dependent $\mathrm{MT}$ at $\mathrm{T} 2$. 3\% of the sample that became teacher-dependent MT at T2 was

${ }^{2}$ Sex was included as a covariate in the model but was not a significant predictor for transition probabilities from the first to the second occasion of measurement. For better presentation we report the model without covariates only. 
Table 4 | Transition probabilities.

\begin{tabular}{|c|c|c|}
\hline \multicolumn{2}{|c|}{ Latent class pattern } & \multirow[b]{2}{*}{$\%$ of sample } \\
\hline T1 class & T2 class & \\
\hline 1 & 1 & 12.5 \\
\hline 1 & 2 & 7.4 \\
\hline 1 & 3 & 0.9 \\
\hline 1 & 4 & 6.0 \\
\hline 2 & 1 & 4.6 \\
\hline 2 & 2 & 21.0 \\
\hline 2 & 3 & 7.4 \\
\hline 2 & 4 & 3.0 \\
\hline 3 & 1 & 0.5 \\
\hline 3 & 2 & 4.5 \\
\hline 3 & 3 & 15.8 \\
\hline 3 & 4 & 2.5 \\
\hline 4 & 1 & 1.6 \\
\hline 4 & 2 & 0.4 \\
\hline 4 & 3 & 5.6 \\
\hline 4 & 4 & 6.6 \\
\hline
\end{tabular}

1 = teacher and peer dependent; 2 = peer-dependent; 3 = independent; 4 = teacher-dependent. Last row shows the proportion of individuals being in a latent class at $T 1$ and $T 2$.

of peer-dependent MT at T1 and $2.5 \%$ of independent MT at $\mathrm{T} 1$.

\section{DISCUSSION}

The purpose of the present study was to extend our understanding of socio-motivational dependency by identifying interindividual differences and intraindividual changes over time in adolescent students' socio-motivational dependency, following a personoriented approach. In a first step, LCA was used to investigate interindividual differences in adolescents' perception of peers and teachers as a source of motivation in ninth and tenth graders. In a second step, LTA were employed to investigate intraindividual changes in this perception from 7th and 8th to 9th and 10th grade.

In accordance with Hypothesis $1 \mathrm{~A}$, the same four types of sociomotivational dependency revealed in grade seven and eight by Raufelder et al. (2013c) could be identified 2 years later: (1) a teacher-and-peer-dependent MT, (2) a teacher-dependent MT, (3) a peer-dependent MT, (4) a teacher-and-peer-independent MT. These findings demonstrate presence of important interindividual differences in students' socio-motivational dependency through adolescence, therefore underlining the validity of the typology itself.

What is important, the proportions of the sample constituting each type changed over time. However, the number of individuals that remained in the same class (55.9\%) was slightly higher than those who changed to another type. In particular, the number of students who are teacher-dependent increased, whereas the group of the teacher-and-peer-dependent MT became smaller over time.
In other words, Hypothesis $1 \mathrm{~B}$ that peers become more important agents during adolescence was not confirmed. There are different explanations for this result. First, peers are still important for students' academic motivation but their influence decreases. Second, the institutional relevance of teachers become more important in ninth or tenth grade, that is, when students' final examines are closer. The teacher is critical when it comes to appraisal of achievement. This finding is in contrasts to those of Goodenow (1993), who found that the importance of the teachers in influencing motivation decreases through adolescence. Third, the teacherand-peer-dependent group is larger than the teacher-dependent group and even a small transition probability from the former to the latter group might result in a large increase in the teacherdependent group. Taken together, the increase in the size of the teacher-dependent MT group suggests an ambivalent role of the teacher-student relationship in middle adolescence.

Nevertheless, the peer-dependent MT group was the largest in size at the second occasion of measurement, which is consistent with the expectation that peers play an important role during adolescence in students' academic motivation (Savin-Williams and Berndt, 1990; Fend, 1998; Brown and Theobald, 1999; Cook et al., 2007). Furthermore, the group of the independent MT did not change in size over time. This finding is important because other research suggest that students of this type seem to have no interest in school (i.e., they show the lowest scores in intrinsic motivation, achievement drive, and performance-approach goals; Jagenow et al., 2014), and, therefore, might be at high risk of school failure. However, the results underline the relevance of the typology and the considerations of strong interindividual differences, as some students show a socio-motivational dependency, while others show constant socio-motivational independence.

The results of the LTA demonstrated a substantial amount of transition across all classes with the smallest amount of mover in the independent MT. This finding is in line with Lerner's developmental contextualism (Lerner, 1986, 1991, 1998) and confirms our Hypothesis 2. Intraindividual changes in the developing adolescence indicate contextual changes in the individuals' school setting. However, it is still unclear why these changes are relevant for some students and for others not. Predictors of the different transition patterns might help to further enhance our understanding. For example, in future research the use of covariates might help to explain changes from one group to another.

For those students who were teacher-and-peer-dependent at the first occasion of measurement and became peer-onlydependent at the second occasion of measurement, the teachers influence the students' motivation lesson students' motivation. The reason might be that teachers' support declines over the years (Bokhorst et al., 2010) and that this subgroup of students are sensible for such changes in the teacher-student relationship. However, almost the same transition probability was found for those becoming teacher-only-dependent from teacher-and-peerdependent, suggesting that peers also can become less important for one's academic motivation in the tested time period. Similarly, peers became less influential for some of the peer-dependent MT individuals, who subsequently switched to the independent MT. One explanation is that even though peer groups become increasingly important through adolescence (e.g., Csikszentmihalyi and 
Larson, 1984), this might not be the case for academic motivation. More research is needed to investigate the subgroups more closely. A high transition probability of becoming an independent MT was also found for those individuals who were previously of a teacher-dependent MT. However, this does not mean that the absolute change over time between the two groups is huge. 5.6\% of the sample was teacher-dependent at the first occasion of measurement and independent at the second occasion of measurement (see Table 4). The finding of low probability of changing from an independent MT to a teacher-and-peer-dependent MT and vice versa is intuitively correct: a student whose motivation is affected by sources other than peers or teachers is unlikely to be substantially influenced by both approximately 2 years later.

Investigation of interindividual differences and intraindividual developmental changes in motivation typologies might facilitate the creation of programs and teaching activities that would support students within the school system based on their social needs in motivation. The typology employed by Raufelder et al. (2013c) important differences in the bidirectional interactions between students and their learning environment (Wigfield and Eccles, 2001). Education curricula and teacher training should take into account these differences in students' motivation styles and how they develop across time. Such an approach would result in a more effective support of each student and accommodating their individual motivation profile. This typology helps to understand the differences in socio-motivational dependency, for example, why and how students interact with their social environment at school in their own specific way and at their own specific pace. In general, in school environments, students are expected to learn and behave uniformly, and students who do not follow these rigid expectations are typically viewed as maladjusted; while, as our research has shown, they just might have different motivational needs.

Our findings suggest that the motivational types should not be regarded or used as fixed labels because such an approach would inhibit an ability to see one's unique potential in this respect, which might very likely change across time. The discussed typology underlines the fact that individuals tend to be socially motivated in various ways, and that a specific form of socio-motivational dependency exhibited by a student might substantially change over time.

The present study complements our understanding of interindividual differences and intraindividual changes in adolescents' socio-motivational dependency. First, we investigated how the influence of teachers and peers on students' academic motivation changes across adolescence, because little is known about these relations after grade eight. Second, we studied the nature of this development by using latent transition analysis. This approach enabled us to describe transitions across different MT that occur over time.

Despite these strengths, the limitations of the present study should be discussed. The current results are limited in their sole reliance on self-report measures. In future studies, teacher-reports should be used in combination with students' self-reports to provide an additional source of evidence in examining differences in students' academic motivation. Notably, studies that included teacher- and self-reports in research on student motivation have reported low levels of concordance between information provided by these sources (Skinner and Belmont, 1993). Furthermore, the longitudinal results should be interpreted considering variations due to changes in students' motivation over the school year, as the data collection at the first time point was at the beginning of the German school year, whereas the data collection at the second time point was at the end of the German school year (see Gehlbach et al., 2012). Moreover, short-time dynamics in peer-relationships that might influence individuals' motivation are not considered in the present study. Further research is necessary to determine personal factors and dispositional motivational characteristics of those individuals. Covariates can be included in LTA models to describe conditions of transition from one to another group.

In conclusion, the current study provided important novel findings regarding students' socio-motivational dependency: across adolescence, for some students peers seem to have a decreasing influence on academic motivation, whereas for others this influence increases within this time period. A similar pattern characterizes the influence exerted by teachers on student academic motivation: for some individuals, teachers become more important in the time period of interest, while for others they do not. Although the magnitude of transition across different MTs was high, the number of students who are teacher-dependent increased and the number of those teacher-and-peer-dependents decreased over time, suggesting that teachers' influence for students' academic motivation might de facto increase across early to middle adolescence, possibly due to their importance for grades obtained in the final exams. Finally, there is an almost stable group of students with socio-motivational independency whose motivational sources should be examined in future studies. Overall, the current findings underline the need of focusing on interindividual differences in adolescents' motivation, which should be considered in daily school life.

\section{ACKNOWLEDGMENTS}

The research reported in this paper was supported by a grant (Schumpeter Fellowship, II/84 452) from the Volkswagen Foundation awarded to Diana Raufelder. The authors would like to thank the principals, teachers, and students for their cooperation in making this study possible.

\section{REFERENCES}

Akaike, H. (1973). "Information theory and an extansion of the maximum likekihood principle," in Second International Symposium on Information Theory, eds B. Petrov and F. Csake (Budapest: Akademiai Kaido), 267-281.

Baker, J. A. (2006). Contributions of teacher-child relationships to positive school adjustment during elementary school. J. Sch. Psychol. 44, 211-229. doi: 10.1016/j.jsp.2006.02.002

Bergman, L. R., and Magnusson, D. (1997). A person-oriented approach in research on developmental psychopathology. Dev. Psychopathol. 9, 291-319. doi: 10.1017/S095457949700206X

Bokhorst, C. L., Sumter, S. R., and Westenberg, P. M. (2010). Social support from parents, friends, classmates, and teachers in children and adolescents aged 9 to 18 years: who is perceived as most Supportive?. Soc. Dev. 19, 417-426. doi: 10.1111/j.1467-9507.2009.00540.x

Brown, B. B. (1990). "Peer groups and peer culture," in At the Threshold: The Developing Adolescent, eds S. S. Feldman and G. R. Elliott (Cambridge, MA: Harvard University Press), 171-196.

Brown, B. B., and Theobald, W. (1999). "How peers matter: a research synthesis of peer influences on adolescent pregnancy," in Peer potential: Making the most of 
how teens influence each other, eds P. S. Bearman, H. Bruckner, B. B. Brown, W. Theobald, and S. Philliber (Washington, DC: National Campaign to Prevent Teen Pregnancy), 27-80.

Cook, T. D., Deng, Y., and Morgano, E. (2007). Friendship influences during early adolescence: the special role of friends' grade point average. J. Res. Adolesc. 17, 325-356. doi: 10.1111/j.1532-7795.2007.00525.x

Crosnoe, R., Cavanagh, S., and Elder, G. H. (2003). Adolescent friendships as academic resources: the intersection of friends, race, and school disadvntage. Sociol. Perspect. 46, 331-352. doi: 10.1525/sop.2003.46.3.331

Csikszentmihalyi, M., and Larson, R. (1984). Being Adolescent: Conflict and Growth in the Teenage Years. New York: Basic Books.

Csikszentmihalyi, M., Larson, R., and Prescott, S. (1977). The ecology of adolescent activity and experience. J. Youth Adolesc. 6, 281-294. doi: 10.1007/bf021 38940

Davidson, A. J., Gest, S. D., and Welsh, J. A. (2010). Relatedness with teachers and peers during early adolescence: an integrated variable-oriented and personoriented approach. J. Sch. Psychol. 48, 483-510. doi: 10.1016/j.jsp.2010.08.002

Deci, E. L., and Ryan, R. M. (2000). Handbook of Self-determination Research. Rochester, NY: University of Rochester Press.

Deci, E. L., and Ryan, R. M. (2008). Facilitating optimal motivation and psychological well-being across life's domains. Can. Psychol./Psychol. Can. 49, 14-23. doi: 10.1037/0708-5591.49.1.14

Dubow, E. F., Tisak, J., Causey, D., Hryshko, A., and Reid, G. (1991). A two-year longitudinal study of stressful life events, social support, and social problem-solving skills: contributions to children's behavioral and academic adjustment. Child Dev. 62, 583-599. doi: 10.1111/1467-8624.ep91090 90183

Eccles, J. S., and Midgley, C. (1990). "Changes in academic motivation and selfperceptions during early adolescence," in Advances in Adolescent Development: From Childhood to Adolescence, eds R. Montemayer, G. R. Adams, and T. P. Gullotta (Newbury Park, CA: Sage), 134-155.

Eccles, J. S., Midgley, C., Wigfield, A., Buchanan, C. M., Reuman, D., Flanagan, C., et al. (1993). Development during adolescence: the impact of stage-environment fit on young adolescents' experiences in schools and in families. Am. Psychol. 48, 90-101. doi: 10.1037/0003-066x.48.2.90

Eccles, J. S., and Wigfield, A. (1998). "Motivation to succeed," in Handbook of Child Psychology, eds W. Damon and N. Eisenberg (New York, NY: John Wiley \& Sons), 1017-1095.

Fend, H. (1998). Eltern und Freunde: Soziale Entwicklung im Jugendalter (Parents and Friends: Social Development During Adolescence). Bern, Switzerlan: Huber.

Furrer, C., and Skinner, E. (2003). Sense of relatedness as a factor in children's academic engagement and performance. J. Educ. Psychol. 95, 148-162. doi: 10.1037/0022-0663.95.1.148

Gehlbach, H., Brinkworth, M. E., and Harris, A. D. (2012). Changes in teacherstudent relationships. Br. J. Educ. Psychol. 82, 690-704. doi: 10.1111/j.20448279.2011.02058.x

Gest, S. D., Welsh, J. A., and Domitrovich, C. E. (2005). Behavioral predictors of changes in social relatedness and liking school in elementary school. J. Sch. Psychol. 43, 281-301. doi: 10.1016/j.jsp.2005.06.002

Goodenow, C. (1993). Classroom belonging among early adolescent atudents: relationships to motivation and achievement. J. Early Adolesc. 13, 21-43. doi: 10.1177/0272431693013001002

Hamre, B. K., and Pianta, R. C. (2001). Early teacher-child relationships and the trajectory of children's school outcomes through eighth grade. Child Dev. 72, 625-638. doi: 10.2307/1132418

Harter, S. (1996). "Teacher and classmate influences on scholastic motivation, self-esteem, and level of voice in adolescents," in Social Motivation - Understanding Children's School Adjustment, eds J. Juvonen and K. R. Wentzel (Cambridge: University Press), 11-42. doi: 10.1017/CBO978051157119 0.004

Hoferichter, F., Raufelder, D., Eid, M., and Bukowski, W. M. (2014). Knowledge transfer or social competence? a comparison of German and Canadian adolescent students on their socio-motivational relationships in school. Sch. Psychol. Int. 35, 627-648. doi: 10.1177/0143034314552345

Hughes, J. N. (2012). Teacher-student relationships and school adjustment: progress and remaining challenges. Attach. Hum. Dev. 14, 319-327. doi: $10.1080 / 14616734.2012 .672288$
Hymel, S., Comfort, C., Schonert-Reichl, K., and McDougall, P. (1996). "Academic failure and school dropout: the influence of peers," in Social Motivation: Understanding Children's School Adjustment, eds J. Juvonen and K. R. Wentzel (New York: Cambridge University Press), 313-345. doi: 10.1017/CBO97805115711 90.015

Jagenow, D., Raufelder, D., and Eid, M. (2014). A person-oriented approach to predict socio-motivational dependency in early adolescents. Learn. Individ. Differ. 36, 173-179. doi: 10.1016/j.lindif.2014.07.017

Juvonen, J., and Wentzel, K. R. (1996). Social Motivation: Understanding Children's School Adjustment. New York, NY: Cambridge University Press. doi: 10.1017/CBO9780511571190

Kenny, R., Dooley, B., and Fitzgerald, A. (2013). Interpersonal relationships and emotional distress in adolescence. J. Adolesc. 36, 351-360. doi: 10.1016/j.adolescence.2012.12.005

Ladd, G. W., Herald-Brown, S. L., and Kochel, K. P. (2009). "Peers and motivation," in Handbook of Motivation at School, eds K. R. Wentzel and A. Wigfield (New York, NY: Routledge), 323-348.

Langeheine, R., and Van de Pol, F. (1990). A unifying framework for markov modeling in discrete space and discrete time. Sociol. Methods Res. 18, 416-441. doi: $10.1177 / 0049124190018004002$

Larson, R., and Richards, M. H. (1991). Daily companionship in late childhood and early adolescence: changing developmental contexts. Child Dev. 62, 284-300. doi: $10.2307 / 1131003$

Lerner, R. M. (1986). Concepts and Theories of Human Development, Vol. 2. New York, NY: Random House.

Lerner, R. M. (1991). Changing organism-context relations as the basic process of development: a developmental contextual perspective. Dev. Psychol. 27, 27-32. doi: 10.1037/0012-1649.27.1.27

Lerner, R. M. (1998). "Theories of human development: contemporary perspectives," in Handbook of Child Psychology, eds W. Damon and R. M. Lerner (New York, NY: John Wiley \& Sons), 1-24.

Levitt, M. J. (2005). Social relations in childhood and adolescence: the convoy model perspective. Hum. Dev. 48, 28-47. doi: 10.1159/000083214

Little, T. D., Cunningham, W. A., Shahar, G., and Widaman, K. F. (2002). To parcel or not to parcel: exploring the question, weighing the merits. Struct. Equ. Modeling 9, 151-173. doi: 10.1207/s15328007sem0902_1

McLachlan, G., and Peel, D. (2000). Finite Mixture Models. New York: Wiley. doi: 10.1002/0471721182

Midgley, C., Feldlaufer, H., and Eccles, J. S. (1989). Change in teacher efficacy and student self- and task-related beliefs in mathematics during the transition to junior high school. J. Educ. Psychol. 81, 247-258. doi: 10.1037/0022-0663.8 1.2.247

Murdock, T. B., Anderman, L. H., and Hodge, S. A. (2000). Middle-grade predictors of students' motivation and behavior in high school. J. Adolesc. Res. 15, 327-351. doi: $10.1177 / 0743558400153002$

Muthén, B. O., and Muthén, L. K. (2000). Integrating person-centered and variable-centered analyses: growth mixture modeling with latent trajectory classes. Alcohol. Clin. Exp. Res. 24, 882-891. doi: 10.1111/j.1530-0277.2000. tb02070.x

Muthén, L. K., and Muthén, B. O. (1999-2012). MPlus Users' Guide (Version 7). Los Angeles, CA: Muthén \& Muthén.

Nylund, K. L., Muthén, B. O., and Asparouhov, T. (2007). Deciding on the number of classes in latent class analysis and growth mixture modeling: a Monte Carlo simulation study. Struct. Equ. Modeling 14, 535-569. doi: 10.1080/10705510701575396

Raufelder, D. (2007). Von Machtspielen zu Sympathiegesten. Das Verhältnis Von Lehrern und Schülern im Bildungsprozess (From Power Games to Sympathy Gestures. The Ratio of Teachers and Students in the Educational Process). Marburg: Tectum.

Raufelder, D., Bukowski, W. M., and Mohr, S. (2013a). Thick description of the teacher-student relationship in the educational context of school: results of an ethnographic field study. J. Educ. Train. Stud. 1, 1-18. doi: 10.11114/jets.vl i2. 108

Raufelder, D., Drury, K. M., Jagenow, D., Hoferichter, F., and Bukowski, W. M. (2013b). Development and validation of the relationship and motivation (REMO) scale to assess students' perception of peers and teachers as motivators in early adolescence. Learn. Individ. Differ. 24, 182-189. doi: 10.1016/j.lindif.2013.01.001 
Raufelder, D., Jagenow, D., Drury, K. M., and Hoferichter, F. (2013c). Social relationships and motivation in secondary school: four different motivation types. Learn. Individ. Differ. 24, 89-95. doi: 10.1016/j.lindif.2012.12.002

Raufelder, D., Jagenow, D., Hoferichter, F., and Drury, K. M. (2013d). The personoriented approach in the field of educational psychology. Probl. Psychol. 21st Century 5, 79-88.

Reeve, J. (2006). Teachers as facilitators: what autonomy-supportive teachers do and why their students benefit. Elem. Sch. J. 106, 225-236. doi: 10.1086/501484

Roeser, R. W., Midgley, C., and Urdan, T. C. (1996). Perceptions of the school psychological environment and early adolescents' psychological and behavioral functioning in school: the mediating role of goals and belonging. J. Educ. Psychol. 88, 408-422. doi: 10.1037/0022-0663.88.3.408

Rohrbeck, C. (2003). "Peer relationships, adolescence," in Encyclopedia of Primary Prevention and Health Promotion, eds T. P. Gullotta, M. Bloom, J. Kotch, C. Blakely, L. Bond, G. Adams, C. Browne, W. Klein, and J. Ramos (New York, NY: Springer), 808-812. doi: 10.1007/978-1-4615-0195-4_118

Rosato, N. S., and Baer, J. C. (2012). Latent class analysis: a method for capturing heterogeneity. Social Work Res. 36, 61-69. doi: 10.1093/swr/svs006

Ryan, A. M. (2001). The peer group as a context for the development of young adolescent motivation and achievement. Child Dev. 72, 1135. doi: 10.1111/14678624.00338

Savin-Williams, R. C., and Berndt, T. J. (1990). "Friendship and peer relationship," in At the Threshold: The Developing Adolecent, eds S. S. Feldman and G. R. Elliott (Cambridge, MA: Harvard Univerity Press), 277-307.

Schwarz, G. (1978). Estimating the dimension of a model. Ann. Stat. 6, 461-464. doi: 10.1214/aos/1176344136

Skinner, E. A., and Belmont, M. J. (1993). Motivation in the classroom: reciprocal effects of teacher behavior and student engagement across the school year. J. Educ. Psychol. 85, 571-581. doi: 10.1037/0022-0663.85.4.571

Skinner, E. A., Zimmer-Gembeck, M. J., Connell, J. P., Eccles, J. S., and Wellborn, J. G. (1998). Individual differences and the development of perceived control. Monogr. Soc. Res. Child Dev. 63, 1-220. doi: 10.2307/1166220

Vermunt, J. K. (2010). Latent class modeling with covariates: two improved threestep approaches. Polit. Anal. 18, 450-469. doi: 10.1093/pan/mpq025

von Eye, A., and Bergman, L. R. (2003). Research strategies in developmental psychopathology: dimensional identity and the person-oriented approach. Dev. Psychopathol. 15, 553-580. doi: 10.1017/S0954579403000294

Wentzel, K. R. (1998). Social relationships and motivation in middle school: the role of parents, teachers, and peers. J. Educ. Psychol. 90, 202-209. doi: 10.1037/00220663.90.2.202

Wentzel, K. R. (2009a). "Peer relationships and motivation at school," in Handbook of Peer Interactions, Relationships, and Groups, eds K. H. Rubin and W. M. Bukowski (New York, NY: Guilford), 531-547.
Wentzel, K. R. (2009b). "Students' relationships with teachers as motivational context," in Handbook of Motivation at School, eds K. R. Wentzel and A. Wigfield (New York, NY: Routledge), 301-322.

Wentzel, K. R., and Asher, S. R. (1995). The academic lives of neglected, rejected, popular, and controversial children. Child Dev. 66, 754-763. doi: 10.1111/j.14678624.1995.tb00903.x

Wentzel, K. R., Battle, A., Russell, S. L., and Looney, L. B. (2010). Social supports from teachers and peers as predictors of academic and social motivation. Contemp. Educ. Psychol. 35, 193-202. doi: 10.1016/j.cedpsych.2010.03.002

Wentzel, K. R., Donlan, A., and Morrison, D. (2012). "Peer relationships and social motivational processes," in Peer Relationships and Adjustment at School, eds A. M. Ryan and G. W. Ladd (Charlotte, NC: Information Age), 79-107.

Wigfield, A., and Eccles, J. S. (2001). Development of Achievement Motivation. San Diego, CA: Academic Press.

Wigfield, A., Eccles, J. S., and Rodriguez, D. (1998). “The development of children's motivation in school contexts," in Review of Research in Education, eds P. D. Pearson and A. Iran-Nejad (Washington, DC: American Educational Research Association), 73-118.

Youniss, J. (1980). Parents and Peers in Social Development. Chicago: University of Chicago Press.

Zimmer-Gembeck, M. J., Chipuer, H. M., Hanisch, M., Creed, P. A., and McGregor, L. (2006). Relationships at school and stage-environment fit as resources for adolescent engagement and achievement. J. Adolesc. 29, 911-933. doi: 10.1016/j.adolescence.2006.04.008

Conflict of Interest Statement: The authors declare that the research was conducted in the absence of any commercial or financial relationships that could be construed as a potential conflict of interest.

Received: 16 December 2014; accepted: 07 February 2015; published online: 25 February 2015.

Citation: Jagenow D, Raufelder D and Eid M (2015) The development of sociomotivational dependency from early to middle adolescence. Front. Psychol. 6:194. doi: 10.3389/fpsyg.2015.00194

This article was submitted to Educational Psychology, a section of the journal Frontiers in Psychology.

Copyright (C) 2015 Jagenow, Raufelder and Eid. This is an open-access article distributed under the terms of the Creative Commons Attribution License (CC BY). The use, distribution or reproduction in other forums is permitted, provided the original author(s) or licensor are credited and that the original publication in this journal is cited, in accordance with accepted academic practice. No use, distribution or reproduction is permitted which does not comply with these terms. 